
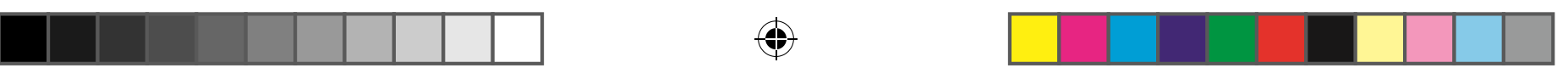

\title{
RESISTÊNCIA QUILOMBOLA: CONFLITOS SOCIOAMBIENTAIS, INJUSTIÇA AMBIENTAL E LUTA POR DIREITOS
}

RESISTANCE QUILOMBOLA: SOCIOENVIRONMENTAL CONFLICTS, ENVIRONMENTAL INJUSTICE AND STRUGGLE FOR RIGHTS

Déborah Luíza Moreira ${ }^{1}$

Michelle Jaber-Silva ${ }^{2}$ Michèle Sato ${ }^{3}$

\section{RESUMO}

O processo de colonização e desenvolvimento do Brasil assentado na colonialidade produziu um país extremamente desigual e um complexo quadro de injustiça ambiental. A educação ambiental (EA) como aliada nas lutas por justiça social e proteção ecológica pode ser uma maneira de fortalecer as lutas e a resistências

1 Doutoranda em Educação pela Universidade Federal de Mato Grosso (UFMT), na linha de pesquisa Movimentos Sociais, Políticas e Educação Popular, membro do Grupo pesquisador em Educação Ambiental Comunicação e Arte (GPEA).

2 Professora Doutora da Universidade Federal de Mato Grosso (UFMT), membro do Grupo Pesquisador em Educação Ambiental Comunicação e Arte (GPEA).

3 Professora Titular da Universidade Federal de Mato Grosso, coordenadora do Grupo Pesquisador em Educação Ambiental Comunicação e Arte (GPEA). 
nos oprimidos por este desenvolvimento. O objetivo deste artigo é aumentar a visibilidade de uma comunidade quilombola de Mato Grosso que há mais de um século grita forte por justiça socioambiental, e que, no entanto, têm suas vozes abafadas pelo sistema excludente. A metodologia utilizada foi Mapa Social com técnicas de entrevista e oficinas. Compreendendo que natureza e cultura são dimensões inseparáveis e que nas lutas ambientalistas incluem-se também a luta contra as injustiças ambientais, trilhamos essa caminhada investigativa pelo viés da EA e oferecemos um retrato sobre as violações de direitos e a luta dessa comunidade para permanecer no território.

Palavras-chave: Educação Ambiental Popular. Quilombo. Justiça Ambiental. Violaçãode Direitos.

\section{ABSTRACT}

The process of colonization and development of Brazil through coloniality carried out an extremely unequal and a complex status quo of environmental injustice. Environmental Education (EE) as a focus to the struggles for social justice and ecological protection may be a way of strengthening the fights and resistance of those oppressed by this development. This article aims at increasing the audience of a "Quilombo's" Community of Mato Grosso that for more than a century has been claiming for socio-environmental justice, and yet, have their voices inaudible by the exclusionary system. The methodology used was the Social Mapping with interview techniques and workshops. Understanding that nature and culture are inseparable dimensions and that environmental challenges include the struggle against environmental injustice, we followed this research's path through the EE and presented a representation on theviolation of rights and the fight of this community to remain in the territory.

Keywords: Popular Environmental Education. Quilombo. Environmental Justice. Violation of Rights. 


\section{INTRODUÇÃO}

No atual sistema econômico, os componentes abióticos e bióticos foram monetizados e transformados em recursos, sobre essa lógica exploratória avolumam-se os dilemas e injustiças ambientais que, por sua vez, possuem forte ligação com exclusão social, sendo urgente relacionar essas injustiças com as questões de direitos humanos e da terra (COSENZA; KASSIADOU; SÁNCHEZ, 2014). As demandas por bens naturais e serviços ambientais são pensadas apenas do ponto de vista do capital, que tende a esvaziar o debate político das questões, excluindo das pautas os grupos humanos que vivem nestes ambientes e colocando seus interesses como subjacentes aos da elite econômica. Os entusiastas deste modelo buscam o desenvolvimento sustentável sem alterar os padrões de produção/consumo e desrespeitam todas as formas de vidas não humanas e os componentes naturais (SATO, 2008).

Ao contrário dos que endossam o desenvolvimento sustentável e a concepção tradicional da educação ambientais (EA), coadunamos com o entendimento de que

[...] a sustentabilidade jamais poderá ser representada por um conceito hegemônico, porque as realidades não são iguais. $O$ corpo instituído pela educação ambiental não é uma patologia do capitalismo e visa a construir um ser sensível, que se adensa na polissemia de sentidos, ainda que esta seja uma tarefa de Sísifo e que, mesmo empurrando a pedra com tanta expectativa, sucumbamos à ação gravitacional na inevitável metáfora dos poderes globais. Apesar disso, um fio de esperança surge aos que ainda acreditam na construção de sociedades sustentáveis em vez de crer no desenvolvimento sustentável (SATO, 2008, p.5).

E com este fio de esperança, sem acreditar em modelos de sociedade e receitas prontas, a EA (SATO, 2001, 2008, 2013, 2016) é uma possibilidade dos seres humanos (EU), enquanto seres inconclusos, reaprenderem a se colocar no mundo, de maneira que aprendam a respeitar as diferentes formas de vidas, os componentes naturais não vivos e as diversas identidades e modos de viver dos grupos em seus territórios (KAWAHA- 
RA, 2015), que na lógica capitalista de exploração dos "recursos" são desrespeitados e invisibilizados (OUTRO) (SILVA, 2011), estabelecendo, deste modo, outra relação com o ambiente (MUNDO). É preciso que as dimensões Indivíduo, Sociedade e Natureza sejam reconectadas.

A EA, inspirada na Fenomenologia, nos ajuda a compreender que, para além de uma mudança de atitude centrada no Eu, é necessário desenvolver o espírito de comunidade e respeito ao Outro, com a preocupação e o cuidado com os diversos componentes que formam o Mundo (SATO, 2001; SATO; PASSOS, 2002, 2009; SILVA; JABER-SILVA; SATO, 2010; SATO, 2011). E, neste caso, a pedagogia não pode ser conservadora ou tradicional, mas a da esperança e da amorosidade, capaz de promover a reconciliação dos seres humanos entre si e com as coisas; mas também a pedagogia do oprimido tendo a educação como prática de liberdade (FREIRE, 1987) para fortalecer nos excluídos pelo sistema econômico a resistência contra esse modelo homogeneizante, que desrespeita toda lógica que não seja a da financeirização da terra e dos componentes naturais, responsável pela degradação social e ambiental.

Entre tantas vertentes relevantes sustentadas por arcabouços conceituais e práticas consistentes, damos relevo ao caráter político da educação ambiental e nos posicionamos contra o desenvolvimento hegemônico, antropocêntrico e meritocrata, que polui ecossistemas, devasta paisagens naturais, e expulsa pessoas do campo, formando nas periferias das cidades verdadeiras zonas de sacrifício humano.

Essas pesquisadoras compreendem que natureza e cultura são dimensões inseparáveis e nas lutas ambientalistas incluem-se também a luta contra as injustiças do sistema econômico desigual, que recai principalmente sobre as populações negras, os povos indígenas e os pobres; à medida que optamos pela vida e pelos "esfarrapados do mundo" a educação popular vem agregar significados às experiências de pesquisa e militância em EA. Por isso, propomos a pensar e sustentar a educação ambiental popular nos trabalhos com populações em condição de vulnerabilidade, como é o caso da comunidade que damos visibilidade neste texto.

Nessa linha, este artigo está alicerçado nos princípios da educação ambiental e da educação popular, ou seja, nos princípios da Educação 
Ambiental Popular, que valoriza a identidade social do grupo, não se apega a verdades absolutas e reconhece os diferentes saberes sem hierarquias, unindo política e educação progressista no diálogo sobre cultura e ambiente na busca por justiça ambiental.

Nas próximas secções, apresentamos nossa opção metodológica e trazemos um pouco dos conflitos socioambientais e violações de direitos enfrentadas por uma população descendentes de escravizados que há mais de um século luta para existir no território ${ }^{4}$ ancestral. Este lócus de resistência é conhecido como complexo Quilombola de Mata Cavalo, localizado em área rural do município de Nossa senhora do Livramento - Mato Grosso, Brasil.

\section{CAMINHOS METODOLÓGICOS}

Para compreender o complexo cenário das injustiças ambientais e violações de direitos humanos e da terra utilizamos a metodologia Mapa Social (SILVA, 2011), que por sua vez possibilita registrar identidades, conflitos socioambientais, injustiças ambientais e táticas de resistência. Essa metodologia permite tanto o uso de oficinas como de entrevistas.

O Mapa Social possibilita que os participantes registrem seus modos de vida, suas lutas e formas de organização, fortalecendo assim a identidade, "[...] narrar-se é também um processo de construção identitária que revisita o pretérito ajustando a existência presente [...]" (SILVA, 2011, p.46). Revisitar a memória por meio das narrativas é fundamental para compreensão de como os impactos ambientais afetam o modo de vida e geram conflitos. Assim sendo, essa metodologia busca ouvir os sujeitos locais e propõe pensar a cartografia a partir das identidades coletivas, dando destaque à dimensão cultural e aos aspectos socioambientais na busca por compreender as dimensões dialógicas habitantes-hábitos-habitats (SILVA, 2011, p. 47).

4 Destacamos que no Brasil a "territorialidade quilombola, têm sido conquistada pelo reconhecimento (identidade étnica/racial e política), pela identificação (da comunidade) e pela titulação (da terra e do território). [...] Entretanto, os governos democráticos constituídos, apresentaram concessões, mais não tiveram, a capacidade de prover, ainda, o novo ordenamento territorial do Estado brasileiro." (SANTANA-FILHO, 2014, p. 217). 
As características desta metodologia, os valores ideológicos que alicerçaram a proposta e o nosso desejo de valorizar as histórias, as narrativas, a cultura e a luta quilombola pelo território justificam nossa escolha metodológica.

Para obter as informações que compõem este artigo, realizamos duas oficinas de Mapa Social e entrevistas com 12 participantes das oficinas. As oficinas foram realizadas na Escola do Quilombo. Participaram do primeiro encontro 64 pessoas, entre elas: moradores da comunidade, estudantes do ensino médio e profissionais da educação. A segunda oficina foi realizada apenas com os sujeitos entrevistados, ou seja, 12 pessoas, sendo 4 estudantes do ensino médio, 4 professoras e 4 moradores/as do quilombo.

Além das entrevistas e das oficinas, realizamos inúmeras visitas ao quilombo. Vivenciar e participar de atividades cotidianas com os/ as moradores/as foi fundamental para dar visibilidade às injustiças ambientais e negações de direitos que este artigo se propõe analisar.

Ressaltamos que os resultados aqui apresentados são parte de uma pesquisa maior que foi submetida à Plataforma Brasil e autorizada pelo Comitê de Ética da Universidade Federal de Mato Grosso (UFMT). O uso das fotos e trechos das entrevistas foi autorizado pelos/as participantes por meio do Termo de Consentimento Livre Esclarecido (TCLE). Para resguardar a identidade das/os entrevistadas/os, atribuímos outros nomes a elas/eles, os nomes usados são de personagens da resistência negra e de militantes das causas étnico-raciais.

Para destacar no texto as narrativas dos/as parceiros/as desta pesquisa, utilizamos o símbolo que representa a luta da comunidade de Mata Cavalo de Baixo (Figura 01):

Figura 01: Símbolo da luta da comunidade de Mata Cavalo de Baixo, Quilombo Mata Cavalo.

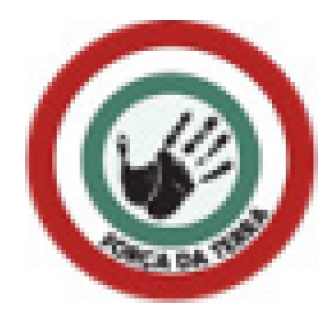

Fonte: Associação da Comunidade de Mata Cavalo de Baixo 


\section{INJUSTIÇAS, VIOLAÇÕES DE DIREITOS E RE-EXISTÊNCIA NO QUILOMBO}

De acordo com o Instituto de Colonização e Reforma Agrária, vivem no Quilombo de Mata Cavalo 418 famílias (BRASIL, 2015), distribuídas em seis comunidades: Aguassú, Estiva/Ourinhos, Mata Cavalo de Cima, Mata Cavalo de Baixo, Mutuca e Capim Verde (Figura 02). No entanto, de acordo com a presidente da Associação dos Produtores Rurais de Mata Cavalo de Baixo, somente na comunidade da qual faz parte, vivem 380 famílias. Essa informação obtida durante a entrevista, nos permite concluir que os dados do Instituto Nacional Colonização e Reforma Agrária (INCRA) estão desatualizados.

Figura 02: Mapa das comunidades que formam o Quilombo e dos marcos históricos do Quilombo de Mata Cavalo, Mato Grosso, 2017.

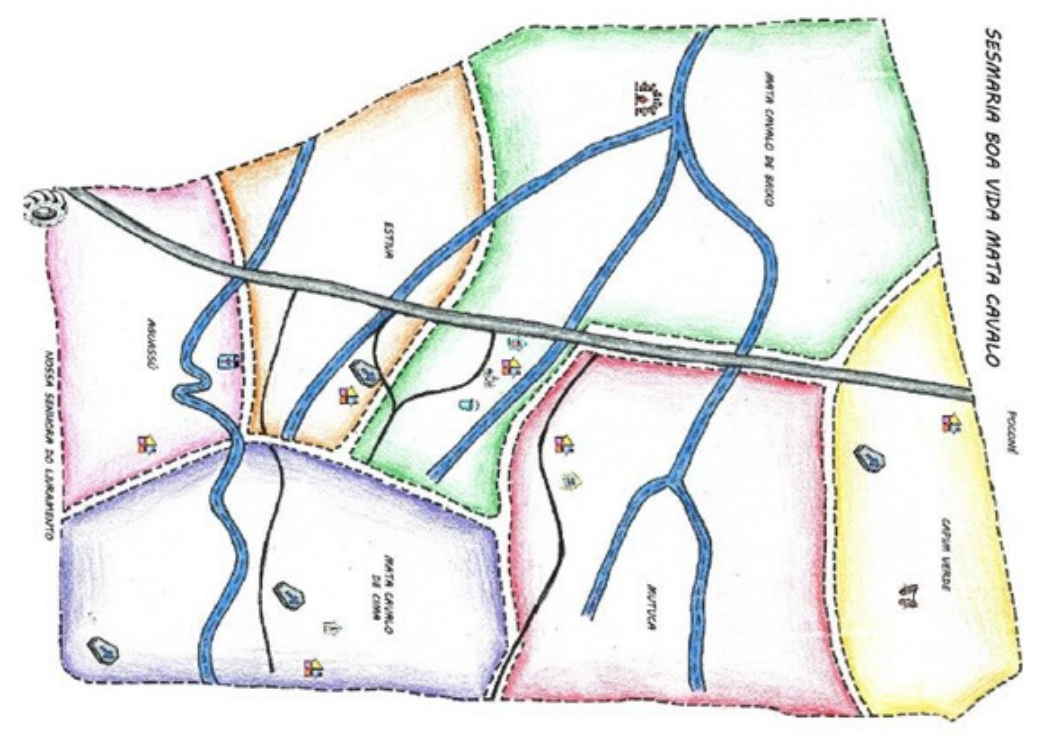

SESMARIA BOA VIDA MATA CAVALO

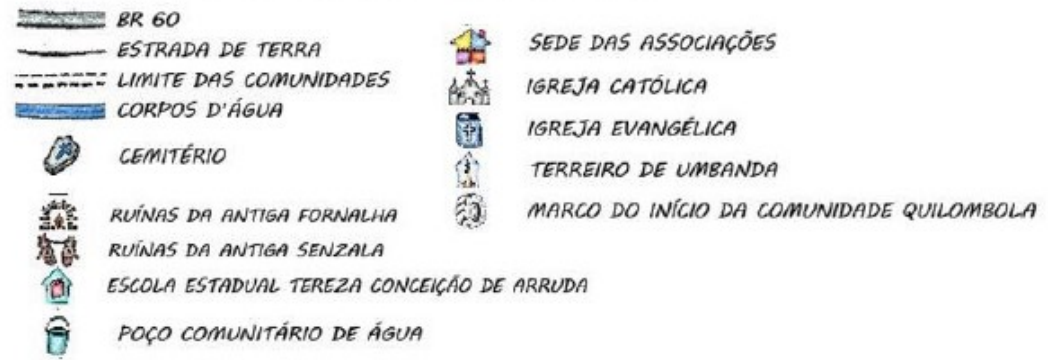

Fonte: Arte: Cristiane Almeida; Organização:

Cristiane Almeida e Déborah Moreira, 2017. 
Cientes de que as resistências ocorrem nos territórios onde os grupos vulnerabilizados resistem e afirmam os seus modos de vida, é nesses espaços que nós, educadoras ambientais apropriadas dos sentidos da educação popular de Paulo Freire, fomos dialogar e nos educarmos coletivamente, com entendimento de que "ninguém liberta ninguém, ninguém se liberta sozinho: os homens [e as mulheres] se libertam em comunhão" e mediatizados pelo mundo (FREIRE, 1987, p. 29). Daí decorre a relevância de promover diálogos e processos educativos em EA junto aos grupos sociais que fazem as resistências. Essas ações potencializam a EA por meio da partilha de saberes socioambientais que revelam muito das desigualdades e injustiças ambientais, assim, a reflexão sobre o cotidiano é base para elaboração de novos saberes (CARDOSO, 2012, p. 116). Deste modo, damos aqui visibilidade às violações que sobretudo ressaltam a potência da força e união traduzida em resistência.

As condições de vida em Mata Cavalo são bastante precárias, assim como em outras comunidades quilombolas do Brasil essa situação está relacionada ao "[...] conflito sobre a posse das terras e também à precariedade do acesso à infra-estrutura básica, necessária para a efetivação de condições de vida dignas" (Coordenação Nacional de Articulação das Comunidades Negras Rurais Quilombolas - CONAQ, 2010, 278). É importante destacar que esse conflito iniciou há mais de 100 anos, após a morte de Ana Tavares (ex-dona dos/as escravizados/as), que por meio de testamento doou para eles/elas parte das terras de Mata Cavalo. Desde então, os/as moradores/as foram vítimas de vários grupos, que, sob a lógica capitalista, interessados no lucro que poderiam obter com a exploração dessa terra, desrespeitaram, ameaçaram e expulsaram inúmeros negros/as da Sesmaria. Iniciando um forte e constante processo de expropriação, com a participação de fazendeiros, garimpeiros e grileiros, legitimados por políticas desenvolvimentistas.

Esses conflitos agravam a situação de vulnerabilidade, insegurança e a dificuldade de acesso às políticas públicas específicas para a população (LEITE, 2010; OLIVEIRA, 2010; OLIVEIRA; SILVA; DIAMANTINO, 2010; MARIN; SILVA; TRINDADE; QUEIROZ, 2010; SILVA, 2010; ARRUTI, 2010). Tanto a precariedade habitacional quan- 
to a dificuldade de acesso às políticas públicas corroboram para o nosso entendimento de que esta população é vítima de racismo ambiental. Este racismo "não se configura apenas através de ações que tenham uma intenção racista, mas, igualmente, através de ações que tenham impacto "racial", não obstante a intenção que Ihes tenha dado origem" (PACHECO, 2008, p. 723).

Grande parte das casas do quilombo são de palhas de babaçu e madeira e precisam ser refeitas de tempos em tempos, o que se torna mais difícil a cada dia, devido à escassez de matéria prima em função dos desmatamentos causados principalmente pelos expropriadores (Quadro de figuras 03). Por meio da associação comunitária de Mata Cavalo de Baixo, a população tem tentado acessar o programa do Governo Federal Minha Casa, Minha Vida, mas esbarram na burocracia e na falta de apoio técnico, conforme denuncia a entrevistada:

O nosso projeto está parado na Caixa Econômica, a funcionária disse que tem erro e que precisamos da ajuda de um assistente social pra arrumar, mas onde nós vamos conseguir? No ano passado pedimos para o governo de Mato Grosso doação de madeira apreendida pelo IBAMA para construirmos 30 casas, eles mandaram 30 metros, o que não dá para construir nem uma casa (Antonieta Barros, 2016, Mata Cavalo).

Quadro de figuras 03: Casas da comunidade de Mata Cavalo de Baixo, Quilombo Mata Cavalo em 2015.

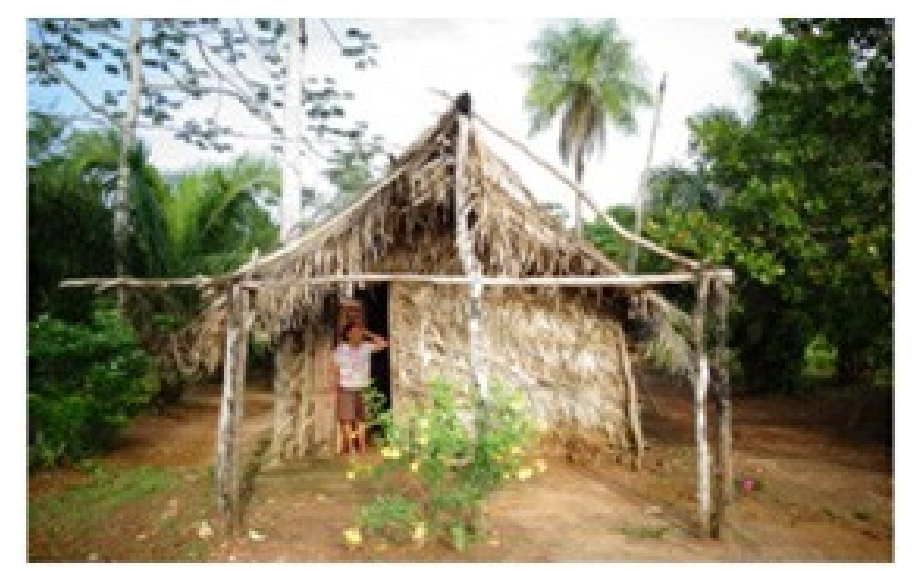




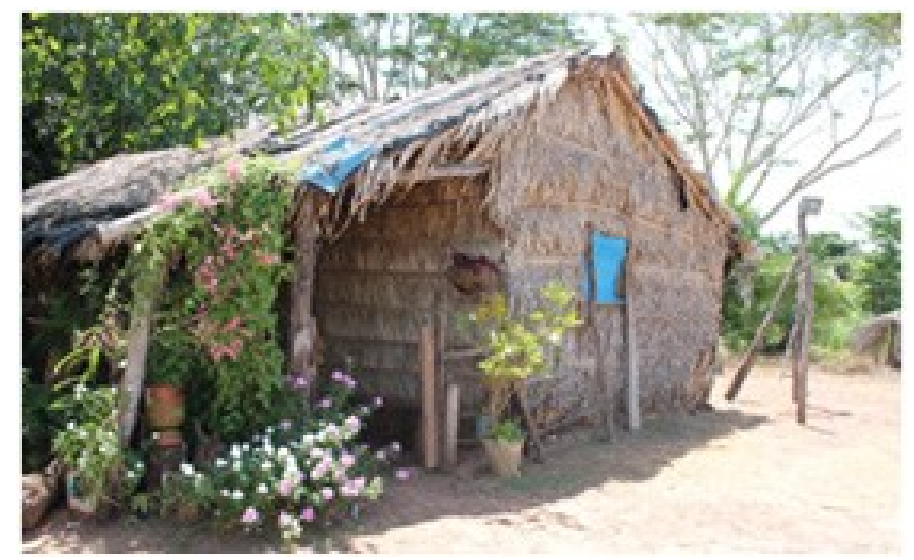

Fonte: Arquivo pessoal de Déborah Moreira; Nicolas Lyra, 2015.

Situação semelhante também é verificada no quilombo de Marambaia, Rio de Janeiro, onde "[...] o primeiro e mais fundamental dispositivo de precarização da vida na ilha incide, sobre o direito à moradia [...]" (ARRUTI, 2010), assim como no quilombo de Mata Cavalo e em tantos outros do Brasil.

Nos inserimos na perspectiva crítica da educação ambiental e coadunamos com Barrozo e Sánchez (2015, p. 2), no entendimento de que as "bases do racismo, na perspectiva da modernidade, da colonialidade e do capitalismo convergem com as origens da degradação ambiental e das desigualdades sociais que recaem sobre as populações de matriz africana no Brasil". Alier (2007) observa que essas populações têm dificuldades em defender seus interesses no campo econômico.

No caso das/os moradoras/es do quilombo, a população tenta ter acesso a meios materiais que proporcionem uma vida com qualidade, mas padecem com a falta de apoio e burocracia do Estado brasileiro. Vítimas de injustiça e racismo ambiental, são obrigados/ as a suportar uma carga desproporcional dos problemas socioambientais em função da expropriação de suas terras. Coadunamos com Souza e Oliveira (2004, p. 2), na perspectiva de que o racismo ambiental pode ser causado tanto por agentes públicos e/ou privados, "mediante ação ou omissão que afetam o ambiente e a qualidade de vida das comunidades baseando-se para tanto em raça, classe, gênero, casta, etnia ou origem nacional." 
Apesar do programa do Governo Federal Luz para Todos, com intuito de promover o acesso a energia elétrica para populações do campo, os/as moradores/as de Mata Cavalo ainda sofrem com a falta de acesso a este benefício, pois muitas casas não possuem energia elétrica. Pouquíssimas residências têm água encanada. Além disso, a comunidade também não dispõe de nenhum serviço de saneamento básico. No caso da comunidade de Mata Cavalo de Baixo, os/as moradores/as que não possuem água encanada buscam água no poço comunitário (Quadro de figuras 04).

Quadro de figuras 04: Poço de água comunitário que abastece parte da população da Comunidade de Mata Cavalo de Baixo, Quilombo Mata Cavalo, 2015.

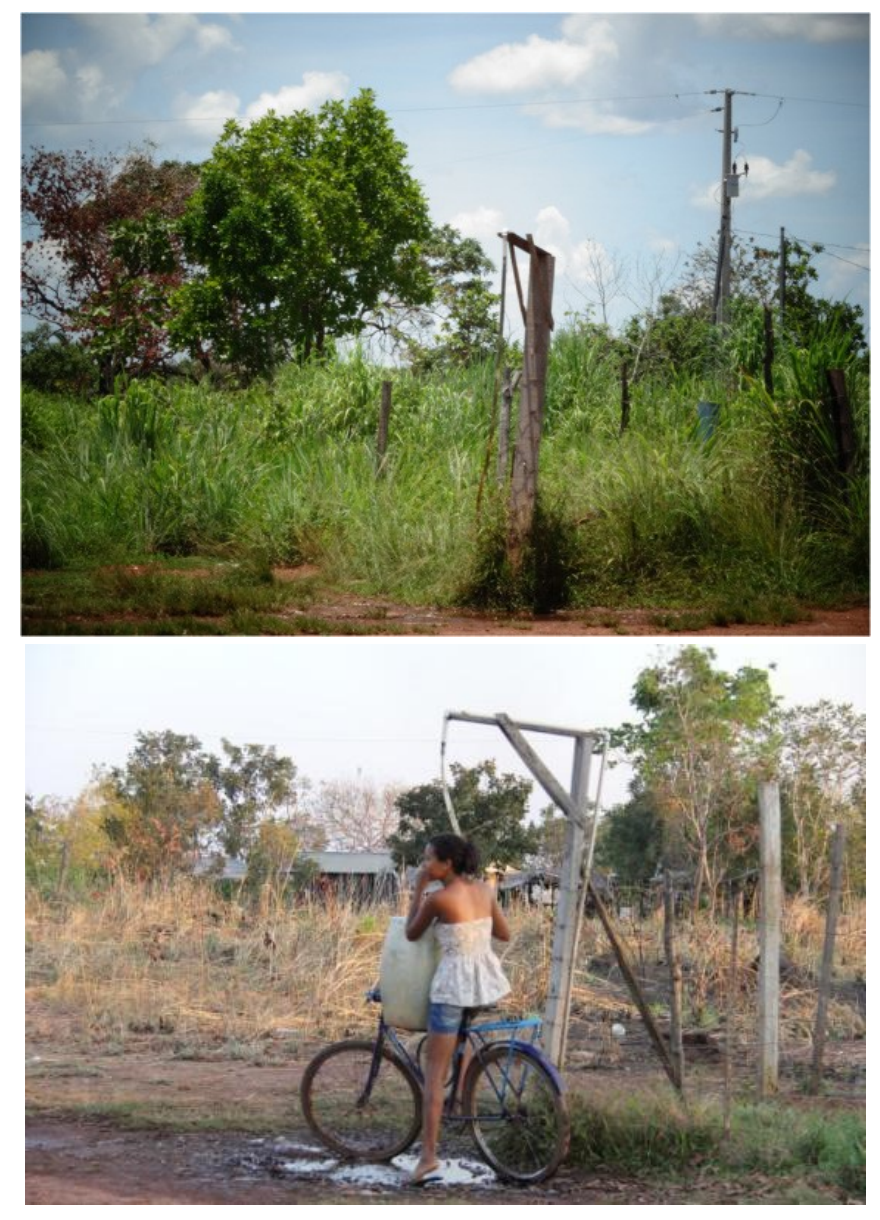

Fonte: Arquivo GPEA, 2015. 
As precárias condições habitacionais e de saneamento vivenciadas por esta população configuram a realidade de grande parte das populações quilombolas no Brasil (ALMEIDA, 2010). Vivemos no século $\mathrm{XXI}$, mas a maioria dessa população vive como no século XVI. Apesar de ser um dos esteios que estruturam essa precariedade, o Governo Federal divulgou, em 2013, um relatório sobre as condições de vida das populações quilombolas do Brasil, nele mais de $60 \%$ das lideranças entrevistadas relatam que não houve melhoras na infraestrutura de esgoto e água após a titulação do território (BRASIL, 20135, p. 5). Acreditamos que a situação concreta seja bem mais precária do que a revelada, posto que o método privilegiado para obtenção das informações foi o quantitativo, e somente foram "[...] pesquisadas 169 comunidades quilombolas que obtiveram título de posse coletiva da terra, emitido entre 1995 e 2009 pelo INCRA" (BRASIL, 2013, p. 2). No entanto, esse dado nos dá pistas sobre a degradante vida da população quilombola do Brasil.

"Os conflitos territoriais, a falta de saneamento básico e de acesso a outras políticas públicas, são elementos que incidem para a situação de insegurança alimentar em muitas das comunidades, [...]" (CONAQ, 2010, 279). Em Mata Cavalo, somam-se as precariedades estruturais de moradia a falta de soberania alimentar. Arruti (2010, p.112) destaca que no quilombo de Marambaia/Rio de Janeiro, "[...] o segundo dispositivo de precarização da vida incide sobre o direito à subsistência".

No caso de Mata Cavalo, devido à ausência de regularização fundiária, os fazendeiros estão dentro do território, exercendo normalmente as atividades econômicas e degradando o ambiente, enquanto a população quilombola vive em espaços reduzidos, às margens da BR 060 e das estradas vicinais, sendo obrigados/as a cultivarem pequenos roçados.

A Coordenação Nacional de Articulação das Comunidades Negras Rurais (CONAQ) mostra que

5 Relatório foi produzido durante o governo do Partido dos Trabalhadores. 
[...] a proporção de crianças quilombolas de até cinco anos desnutridas é $76,1 \%$ maior do que na população brasileira [...]. A incidência de crianças com déficit de peso para a idade nessas comunidades é de $8,1 \%$, maior do que entre as crianças do semi-árido brasileiro (2010, p.279).

Em Mata Cavalo a situação não é muito diferente da denunciada pela (CNAQ), a população passou de camponeses/as que produziam praticamente tudo o que era necessário para o sustento à situação de fome, cerceados/as em seu próprio território (BARROS 2007; CASTILHO, 2011).

\section{QUILOMBO MATA CAVALO: LÓCUS DE LUTA E RESISTÊNCIA}

A regularização fundiária seria "[...] uma medida de reparação histórica em relação à opressão sofrida desde o tempo da escravidão, de um grupo que continuou a ser alvo de violência e preconceitos muito tempo depois da Lei Áurea" (CAVIGNAC, 2010).

As entrevistas realizadas com os/as quilombolas evidenciaram que apesar das violações de direitos fundamentais e da exclusão socioeconômica, a população resiste e aguarda que o Estado burocrático brasileiro indenize os fazendeiros (expropriadores), para retornarem ao espaço de cada família e construírem suas casas, cultivarem a terra e concretizarem o sonho de uma vida sem tantas injustiças. $O$ sentimento de pertencimento ao território ocupado pelos ancestrais e o desejo de continuar nele sobressaem diante das dificuldades vivenciadas diariamente, conforme narrado:

[...] meu pai que lutou aqui, ele morreu aqui, ele pediu pra mim: minha filha, eu lutei com o fazendeiro, como você gosta daqui a terra é sua; então eu não tenho vontade de sair daqui, eu como o pão que o diabo amassou, mas eu não saio, não saio daqui (Anastácia, 2015, Mata Cavalo). 
O território é fundamental para a manutenção da identidade do grupo. Em Mata Cavalo, a vivência no território fortalece o sentido de pertencimento a este local que é permeado de significados, com paisagens e histórias de um povo, que desde meados de 1700, sofre e resiste ao modelo explorador escravocrata (Figura 05).

Figura 05: Ruínas da fornalha onde os/as escravizados/as trabalhavam, Comunidade Mata Cavalo de Baixo, Quilombo Mata Cavalo, 2016.

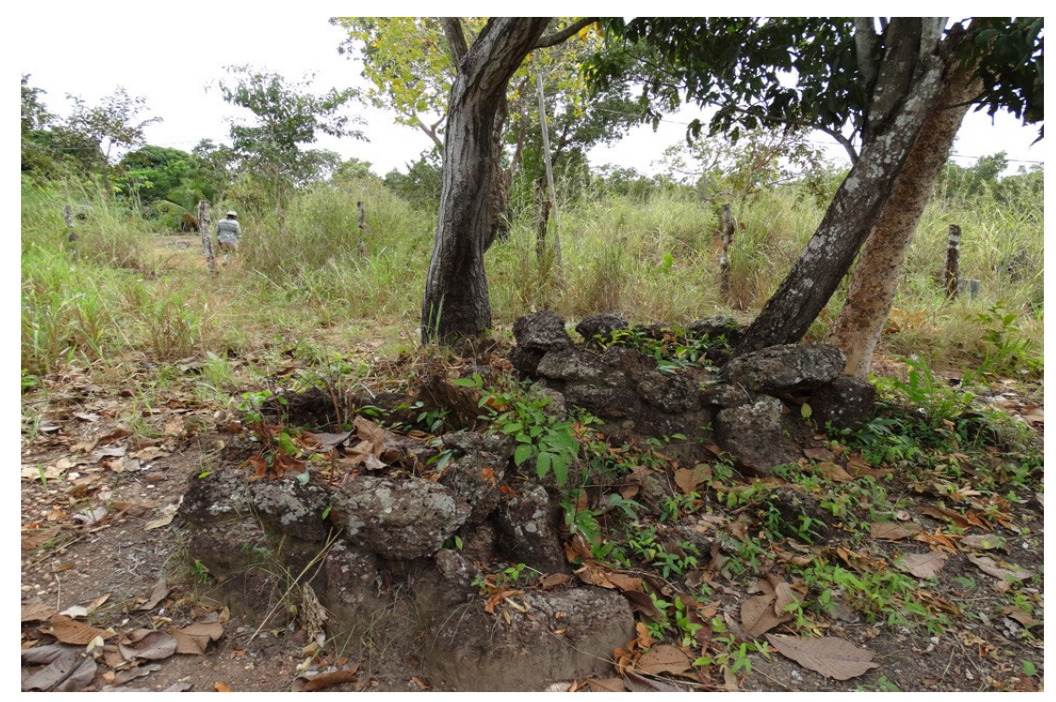

Fonte: Arquivo pessoal de Déborah Moreira, 2016.

$\mathrm{Na}$ comunidade pesquisada, os direitos e garantias fundamentais, assegurados pela Constituição Federal de 1988, são violados diariamente. Destacamos alguns: o direito à moradia, ao saneamento bási$\mathrm{co}, \mathrm{o}$ direito de ir e vir no território, direito à soberania alimentar, direito à saúde, dentre outros; a moradora entrevistada narra as dificuldades enfrentadas para permanecer no quilombo:

Aqui é uma vida sufoco, se nós não tivermos coragem nós não vivemos aqui; isso eu vou falar para você, se nós não dermos duro, aqui nós não vivemos, porque aqui a gente não tem um trator para trabalhar, nós não temos um carro para conduzir as coisas que nós plantamos, não temos ninguém (Anastácia, 2015, Mata Cavalo). 
Considerando o contexto de resistência da população quilombola de Mata Cavalo e sua luta por justiça social, é nesse universo de tensões, conflitos e múltiplas problemáticas em função do sistema mundo-capitalista, assentado na colonialidade do poder, do saber, do ser e da natureza ${ }^{6}$, que a interculturalidade crítica pode se constituir em uma ação pedagógica capaz de auxiliar na construção de outras sociedades.

Na perspectiva de Walsh (2010, p. 4), a interculturalidade crítica é um projeto político, social, ético e epistêmico que afirma a necessidade de mudar além das relações, as estruturas, as condições e os dispositivos de poder que mantém a desigualdade, a inferiorização, a discriminação e a racialização. É importante destacar que essa vertente da interculturalidade tem suas raízes nas discussões políticas protagonizadas pelos movimentos sociais, o que ressalta sua orientação com relação ao problema estrutural-colonial-capitalista e o seu caráter contra-hegemônico (WALSH, 2010).

A colonialidade do poder que classifica negros e indígenas como inferiores, naturaliza a expropriação da terra vivenciada por essas populações e povos. Nesse sentido, a retirada do território ocasionou diversos problemas e dificuldades na vida dos/as quilombolas, um deles é o econômico, a baixa renda das famílias incomoda e aflige a população que aguarda a titulação do território com esperança de melhoria na qualidade de vida:

Como a gente nasceu e criou aqui nesse lugar, a gente tem amor nele, [...]. Você vê, como eu, aqui nós não temos quase renda de nada, tem uma roça, uma lavoura que a gente faz, mas é pequena [...] mas só que agora diz que só tá faltando os

6 A colonialidade possui pelo menos quatro eixos que a estruturam: a colonialidade do poder "refere-se ao estabelecimento de um sistema de classificação social baseada na hierarquia racial e sexual, [...]"; a colonialidade do saber, referente ao "[...] posicionamento de eurocentrismo como a perspectiva única de conhecimento, [...]"; a colonialidade do ser, "exercida através da inferiorização, subalternização e desumanização [...]" de negros e indígenas; a colonialidade da natureza, que "[...] encontra a sua base na divisão binária natureza/sociedade, descartando o mágico-espiritual-social, a relação milenar entre mundos biofísicos, humanos e espirituais, [...]" (WALSH, 2008, p. 138). 
ocupantes (fazendeiros) receberem, acho que aí as coisas vão melhorar [...] (Zumbi, 2015, MATA CAVALO).

No entanto, pesquisas divulgadas pelo Ministério do Desenvolvimento Social (MDS) sobre a situação das comunidades quilombolas tituladas revelam que a melhoria nas condições econômicas foram extremamente sutis e as dificuldades para acessar os serviços de assistência técnica e programas governamentais permanecem muito semelhantes ao que se tinha antes da titulação (BRASIL, 2013; BRASIL, 2014).

Essas informações mostram que apesar dos avanços no campo legal, com o reconhecimento de alguns direitos dessas populações, isto não tem se materializado no campo do vivido. Candau e Russo (2010, p.158) afirmam que "a situação dos afro-descendentes na maior parte do continente Latino Americano tem sido configurada por processos de violência e exclusão física, social e simbólica". Neste contexto, apenas a demarcação "não é suficiente para assegurar a sustentabilidade ecológica e social desses espaços [...]" (JABER-SILVA; SATO, 2012, p.25), é preciso caminhar rumo à construção de outra sociedade.

A população de Mata Cavalo, reconhecida pela Fundação Cultural Palmares em 2000, sonha com a regularização fundiária para melhorar a qualidade de vida. Atualmente padecem com a falta de renda, agravada pelos pequenos espaços que Ihes são destinados para cultivo. Enquanto esta situação perdura, cada família recebe cesta básica, no entanto, uma das entrevistadas denuncia a falta de regularidade no fornecimento deste auxílio. Fato que aumenta a vulnerabilidade da população, além da morosidade na regularização fundiária, que limita a atividade agrícola. Como obter justiça social e redistribuição numa sociedade estruturada na colonialidade e no racismo?

Observamos que as políticas paliativas do Governo Federal, criadas durante a gestão do Partido dos Trabalhadores, não se efetivaram nesse território, ou não atenderam a toda a população, ou não tem regularidade quando se trata da população quilombola de Mata Cavalo. Como exemplo citamos: o "Projeto de Habitação", o "Luz para Todos" e o "Fome Zero". Esta situação nos faz concluir que além de serem 
vítimas de racismo ambiental, os quilombolas sofrem com o racismo institucional por parte Estado Brasileiro, materializado na não efetivação de políticas coordenadas pelo então Ministério da Cidadania e pelo Instituto Nacional de Colonização e Reforma Agrária.

Conhecendo a história escravocrata do Brasil, percebemos que o pano de fundo desta omissão tem relação com a questão racial. Não acreditamos que outro ordenamento social seja possível numa sociedade em que a colonialidade está fortemente presente, é urgente discutirmos com os grupos em situação de vulnerabilidade projetos de educação intercultural e de sociedades para re-existência e bem viver (WALSH, 2009; ROJAS MARTINEZ, 2004).

Urgência que fica ainda mais evidente quando consideramos que os/as moradores/as que já estão nos espaços definitivos, ou seja, que eram ocupados por seus/suas ancestrais, padecem com outro problema: falta de apoio e estrutura para plantar e comercializar os produtos excedentes, conforme relata uma das entrevistadas:

Por que que nós plantamos pouco? Teve um ano aqui, o ano passado, que eu plantei e eu perdi. Eu pedi o carro de uma pessoa daqui se podia arrumar para nos levar na cidade, e ele disse que não podia, [...] nós tínhamos abóbora, quiabo, maxixe, melancia, tudo para levar para lá [Nossa Senhora do Livramento]. [...] então eu fui na prefeitura, aí me disseram que não tinham carro para nós trazermos as coisas para vender [...]. Semana passada eu fui em Livramento [na secretaria de agricultura] ver se tinha trator, disseram que não têm. [...] aqui tá uma dificuldade [...] (Anastácia, 2015, Mata Cavalo).

O trecho expõe as dificuldades e a falta de perspectiva de melhoria da situação econômica e expõe ainda outra questão: a falta de apoio e a discriminação por parte do poder municipal com a população do quilombo.

Em Mata Cavalo, a população padece com a falta de apoio do governo, o que contribui ainda mais para queda na qualidade de vida. Em nosso entendimento, esse descaso é fruto do racismo institucionalizado e da naturalização das situações de violências vivenciadas por estas populações. 
Os poucos empregos que existem na comunidade são oriundos dos contratos da Escola Estadual Professora Tereza Conceição de Arruda, no entanto, o número é bastante reduzido, dos 28 funcionários da unidade escolar, apenas 12 são quilombolas. Uma das entrevistadas narra as dificuldades em função da falta de renda e a melhoria de sua vida após ser contratada para trabalhar na escola:

[...] no começo pra mim era muito difícil, sem emprego, com os filhos, muito difícil [...] aí eu tive a oportunidade de dar aula nas séries iniciais, no terceiro e quarto ano, isso me incentivou a ser professora, então eu fiz faculdade de pedagogia, especialização em educação do campo, e assim minha vida melhorou bastante (Antonieta Barros, 2016, MATA CAVALO).

Todavia, essa não é a realidade da grande maioria, apenas 12 famílias têm alguém trabalhando na escola, o que significa dizer que mais de $95 \%$ das famílias que vivem no quilombo padecem com a falta de renda, agravada pela morosidade da justiça brasileira e ineficiência/ omissão do estado (MOREIRA, 2017). A narrativa abaixo dá mostra das violências e violações sofrida por essa população:

Aqui já teve uma vida muita boa, uma vida boa, aqui para quem viu, para quem nasceu e criou aqui no quilombo do Mata Cavalo, para ver hoje em dia não acredita, [...]. Antigamente não tinha justiça pra pobre, era só quem tinha [dinheiro] e era bem de vida que ganhava questão, os pobres que tinha a suas terra como pai, meu pai tinha 410 hectares de terra, mas acabou de tanto fazendeiro grilar um pedaço, [...] outro chega e grila, outro chega e grila, [...] não tinha justiça, fazer o que? Era ficar corrido, um pra cá, outro pra lá, outro ia embora, desistia [...] (Zumbi, 2015, Mata Cavalo).

Sem poder plantar em sua própria terra, posto que estão confinados/as a espaços reduzidos, aguardando a regularização fundiária, sem regularidade no fornecimento de cesta básica, sem emprego, sem meios para aumentar a renda, sem apoio dos poderes Federal, Estadual e Municipal, ainda assim resistem e re-existem. Alguns qui- 
lombolas são aposentados e recebem um salário mínimo, mas a maioria da população padece sem renda.

Toda omissão do Estado burocrático brasileiro, que para nós é também uma estratégia para desarticular a comunidade, contribui para 0 aumento da criminalidade no quilombo, como narrado:

Outro problema é roubo, assalto, alguns são quilombolas, outros é de fora. Assaltaram uma casa aqui há pouco tempo, levaram várias coisas, amarraram todo mundo [...], outro dia roubaram um carro, na semana passada teve outro roubo, esse nosso problema é também com pessoas que estão vindo de fora, e vem esconder no Mata Cavalo [...] É tráfico de droga que rola dentro da comunidade[...] Antigamente era tranquilo, hoje você não pode mais sair e deixar sua casa que você acha só o buraco, tá desse jeito, antigamente se tinha paz no quilombo, hoje essa violência tá chegando (Antonieta Barros, 2016, Mata Cavalo).

A entrevistada reclama da dificuldade para conseguir apoio do Poder Público para aumentar a segurança no quilombo:

Eu fui na delegacia, conversei, pedi, queria que fizesse algumas rondas, dando umas voltas no quilombo, só pra intimidar mesmo, eles disseram que iriam vir, foi alguns dias, mas parou [...] enquanto não se melhorar as políticas públicas para população quilombola, não vai melhorar a vida no quilombo, e com a saída de Dilma não vai melhorar, principalmente o pobre, esses vão penar (Antonieta Barros, 2016, Mata Cavalo).

O quilombo não é uma ilha isolada. A sociedade em crise reflete dentro e fora do quilombo. Mesmo distante apenas $10 \mathrm{~km}$ da cidade de Nossa Senhora do Livramento, a população não consegue o apoio do Estado burocrático para resolver ou amenizar os problemas cotidianos.

Diante de tantas dificuldades, é na luta comunitária pelo território que o ânimo se renova. Este agrega, fortalece a identidade coletiva, mantém e revitaliza a força necessária para permanecer em Mata Cavalo. A experiência coletiva da luta é extremamente importante para sua continuidade, conforme narra uma das entrevistadas: 
O que me faz permanecer em Mata Cavalo é a luta, [...], a luta pelo quilombo, ser quilombola, hoje eu luto por ela" (Antonieta Barros, 2016, Mata Cavalo).

A Constituição de 1988 inaugurou um novo momento para as populações descendentes de escravizados por meio do reconhecimento de seus direitos territoriais. Contudo, tais avanços que são pouquíssimos têm influenciado na qualidade de vida dessas populações. Para Silva (2010, p. 223) "[...] as comunidades quilombolas estão sendo vítimas de uma grande onda de racismo institucional [...] as vítimas sempre são os que "nunca" tiveram apoio do estado brasileiro; destaco as comunidades quilombolas [...] " O Estado burocrático brasileiro ineficiente e omisso é o responsável pela vulnerabilidade e pela situação de injustiça a que estão expostos esses grupos.

O abandono desses grupos por parte do Poder Municipal, denunciado nas entrevistas, agrava ainda mais a situação de vulnerabilidade. Os serviços de saúde oferecidos a esta população são praticamente inexistentes, como pode ser observado nas narrativas:

Esse ano [mês de maio] ainda não foi contratado nenhum agente de saúde para atender Mata Cavalo, não tivemos nenhuma visita, e a comunidade também não consta na lista de comunidades rurais do município para receber visita de médico. Tudo é difícil quando você fala que é do Mata Cavalo, tudo é mais demorado (Antonieta Barros, 2016).

Aqui a gente não pode ficar doente, se ficar tem que ir para Livramento, e tem que pagar alguém que tem carro pra levar, senão não vai. Para você vê a dificuldade, eu estou sem tomar o remédio da pressão tem dois meses, já fui duas vezes na farmácia da prefeitura para buscar e dizem que não tem, não chegou (Tereza de Benguela, 2015, Mata Cavalo).

Outras comunidades quilombolas também sofrem com problemas semelhantes aos denunciados pelos sujeitos desta pesquisa (ALMEIDA, 2010). Ser quilombola no Brasil, "[...] para além dos elementos culturais, históricos e de um protagonismo, é ser portador um ônus so- 
cial e político que se prolonga há décadas ou quiçá séculos" (RATTS; FURTADO, 2010, p. 240).

Entendemos os descasos relatados pelas/os moradoras/es, que é também vivenciado por comunidades quilombolas do Brasil, como RACISMO. A sociedade brasileira

insistentemente tem negado a existência do racismo e do preconceito racial. Entretanto, as pesquisas têm mostrado aquilo que cotidianamente é retificado e reforçado, e que a lei áurea não foi capaz de romper: a imensa exclusão da população negra [...] (CONAQ, 2010).

Outra denúncia, desta vez sobre falta de coleta de lixo, corrobora a afirmação acima. A prefeitura municipal colocou lixeiras e recolhe os resíduos de diversas propriedades e comunidades rurais, localizadas às margens da BR 060 que também passa no meio do quilombo; contudo, nenhuma lixeira foi colocada em Mata Cavalo. O último ponto de coleta é no assentamento Santana, a menos de 150 metros do início do território quilombola. Ainda foram citados casos de pessoas de fora do quilombo que jogam lixos e entulhos no território:

Muitas vezes a gente sai aí na estrada para Livramento e acha um monte de lixo, caminhão vem despejar aqui. Esses dias mesmo, bem na porta da casa de um dos quilombolas jogaram um monte de lixo, aí ele reclamou, mas depois tirou (Anastácia, 2016, Mata Cavalo).

O problema com a destinação do lixo é realidade na maioria das comunidades quilombolas do Brasil, sendo que, em mais de $90 \%$ das comunidades tituladas não há coleta dos resíduos (BRASIL, 2013, p.5).

Denúncias também foram feitas com relação à precariedade do transporte escolar. Os/as quilombolas se queixam da insegurança do ônibus que transporta crianças e adolescentes para a escola, o veículo é extremamente velho e quebra com muita frequência, interferindo diretamente no rendimento escolar, além de colocar em risco a segurança dos/as usuários deste serviço. 
Olha, nós já reclamamos diversas vezes na prefeitura, que é responsável pelo transporte, mas não adianta. O ônibus que vem pra nós é muito velho, quebra muito, atrapalha, as crianças chegam tarde na escola, chegam tarde em casa, passam da hora de comer. Para você vê: o ônibus que estava carregando nossas crianças não fecha a porta, imagina carregar várias crianças com a porta aberta, um perigo [...] (Lélia Gonzalez, 2016, Mata Cavalo).

Todas estas denúncias fortalecem nosso entendimento de que a população quilombola de Mata Cavalo é vítima de RACISMO INSTITUCIONAL E AMBIENTAL.

Até aqui, apresentamos as denúncias feitas durante as entrevistas e os encontros de mapeamento. Estas demonstram situações de injustiça ambiental que têm recaído de modo implacável sobre a população de Mata Cavalo. Diversas pesquisas demonstram que situações semelhantes também são vivenciadas por outras comunidades quilombolas do Brasil.

\section{ALGUMAS CONSIDERAÇÕES}

A realidade da população de Mata Cavalo mostra que apesar de haverem programas e políticas dedicadas a tornar mais humanizada as condições de vida nas comunidades quilombolas do Brasil, essa população não tem acesso a elas e sofre com a falta de: regularização fundiária, moradia adequada, saneamento básico, acesso à água potável, soberania alimentar, atendimento médico e baixo acesso aos serviços de saúde. Ainda, ineficiência do serviço de assistência técnica rural, falta de renda, ineficiência na segurança pública, aumento da criminalidade, falta de transporte escolar seguro, ausência de coleta de lixo, carência de energia elétrica e péssimas condições das estradas que dão acesso às comunidades que compõem o complexo quilombola de Mata Cavalo.

As violações, negações de direitos e de garantias fundamentais demonstram a omissão, a ineficiência e o racismo institucionalizado no Estado brasileiro. Este caótico cenário, somado às atividades eco- 
nômicas empreendidas pelos expropriadores do território quilombola, gerou conflitos socioambientais que são agravados pela demora na regularização fundiária.

Mata Cavalo é um exemplo de grupo social cujo modo de vida tem profunda relação com o ambiente circundante e que vivem em situação de tensão, em função de um sistema que transforma tudo em mercadoria: terra, água e biodiversidade. Essa lógica moderna monoculturalista tem intensificado a cada dia as situações de injustiça ambiental, ameaçado a cultura e a existência destes grupos, que na disputa por seus territórios lutam para poder existir.

Apesar de conviverem com a negação da humanidade por parte do Estado Brasileiro, salta aos olhos a boniteza da resistência, permeada por solidariedade entre o grupo e encharcada de pertencimento ao território; local fértil de pedagogias insurgentes assentadas na relação habitantes-habitat-hábitos, profícuo para diálogos e aprendizados em educação ambiental popular.

\section{REFERÊNCIAS BIBLIOGRÁFICAS}

ARRUTI, José Maurício. A Negação do Território: Estratégias e Táticas do Processo de Expropriação na Marambaia. In: ALMEIDA, Alfredo Wagner Berno de (Orgs.). [et al]. Cadernos de debates Nova Cartografia Social: Territórios quilombolas e conflitos. Manaus: Projeto Nova Cartografia Social da Amazônia / UEA Edições, 2010. $349 \mathrm{p}$.

BARROS, Edir Pina de. Laudo pericial histórico-antropológico. Mato Grosso: Justiça Federal, 2007.

BARROZO, Luciana Aranda; SÁNCHEZ, Celso. Educação ambiental crítica, interculturalidade e justiça ambiental entrelaçando possibilidades. VIII EPEA - Encontro Pesquisa em Educação Ambiental. Rio de Janeiro, 2015.

BRASIL. INCRA, Instituto Nacional de Colonização e Reforma Agrária. Andamento dos Processos de Regularização de Territórios 
Quilombolas. 2015. Disponível em: <http://www.incra.gov.br/sites/ default/files/uploads/estrutura-fundiaria/quilombolas/andamento_dos_ processos_pdf.pdf>. Acesso em 11 set. 2015.

- Ministério do Desenvolvimento Social e Combate à

Fome. Quilombos do Brasil: segurança alimentar e nutricional em territórios titulados. Cadernos de Estudos Desenvolvimento Social em Debate. Brasília, n. 20, 2014.

- Ministério do Desenvolvimento Social e Combate à Fome. Pesquisa de avaliação da situação de segurança alimentar e nutricional em comunidades quilombolas tituladas. Brasília, out. 2013.

CARDOSO, Ana Maria Ferreira. Tessitura de Saberes Ambientais e Ecopráxis no Movimento Pró-parque Lagoa de Itaperaoba, em Fortaleza. Tese. Programa de Pós-Graduação em Educação, Universidade Federal do Ceará (UFC). Fortaleza, 2012.

CASTILHO, Suely. Quilombo Contemporâneo - Educação, Família e Cultura. Cuiabá: UFMT Editora, 2011.

CANDAU, Vera Maria Ferrão; RUSSO, Kelly. Interculturalidade e Educação na América Latina. Rev. Diálogo Educ., Curitiba, v.10, n.29, p.151-169.

CAVIGNAC, Julie Antoinette. Resorts e Quilombolas - Alianças Políticas e Interesses Econômicos em Sibaúma (RN). In: ALMEIDA, Alfredo Wagner Berno de (Orgs)... [et al]. Cadernos de debates Nova Cartografia Social: Territórios quilombolas e conflitos. Manaus: Projeto Nova Cartografia Social da Amazônia / UEA Edições, 2010. 349 p.

CONAQ. Coordenação Nacional de Articulação das Comunidades Negras Rurais Quilombolas. Manifesto pelos Direitos Quilombolas. In: ALMEIDA, Alfredo Wagner Berno de (Orgs)... [et al]. Cadernos de debates Nova Cartografia Social: Territórios quilombolas e conflitos. Manaus: Projeto Nova Cartografia Social da Amazônia / UEA Edições, 2010. 349 p. 
COSENZA, Angélica; KASSIADOU, Anne; SÁNCHEZ, Celso. Educação Ambiental e Direitos Humanos: necessárias articulações a partir da justiça ambiental e da ecologia política. In: SILVA, A. M. M. S.; TIRIBA, L. (orgs.). Direito ao Ambiente como Direito á Vida: desafios para a educação em direitos humanos. São Paulo: Cortez, 2014.

FREIRE, Paulo. Pedagogia do Oprimido. 11ed. Rio de Janeiro: Paz e Terra, 1987.

JABER-SILVA, Michelle; SATO, Michèle Tomoko. Territórios em tensão: o mapeamento dos conflitos socioambientais do Estado de Mato Grosso - Brasil. Educação e Sociedade, Campinas, vol.15, n.1, p. 1-22. Jan./abr. 2012. ISSN 1809-4422.

LEITE, Ilka Boaventura. Humanidades Insurgentes: Conflitos E Criminalização Dos Quilombos. In: ALMEIDA, Alfredo Wagner Berno de (Orgs)... [et al]. Cadernos de debates Nova Cartografia Social: Territórios quilombolas e conflitos. Manaus: Projeto Nova Cartografia Social da Amazônia / UEA Edições, 2010. 349 p.

KAWAHARA, Lúcia Shiguemi. Currículos festeiros de águas e outonos: fenomenologia da educação ambiental pós-crítica. Tese (Doutorado em Educação) - Programa de Pós-Graduação em Educação, UFMT. Cuiabá: 2015, 287f.

MARIN, Rosa Elizabeth Acevedo; SILVA, Sebastião Menezes da; TRINDADE, Joseline Barreto; QUEIROZ, Silvaneide. Quilombolas do Curiaú: Conflitos Socioambientais não Resolvidos com a Criação da Apa do Curiaú. In: ALMEIDA, Alfredo Wagner Berno de (Orgs) [et al]. Cadernos de debates Nova Cartografia Social: Territórios quilombolas e conflitos. Manaus: Projeto Nova Cartografia Social da Amazônia / UEA Edições, 2010. p. 349.

MOREIRA, Déborah Luíza. Território, luta e educação: dimensões pulsantes nos enfrentamentos dos conflitos socioambientais mapeados no Quilombo de Mata Cavalo. Dissertação de Mestrado. Universidade Federal de Mato Grosso, Instituto de Educação. 2017. $161 f$ 
OLIVEIRA, Mirna Silva; SILVA, Paulo H. Carvalho e; DIAMANTINO, Pedro Teixeira. Abrindo os Braços: A Luta Quilombola de São Francisco do Paraguaçu-Boqueirão. In: ALMEIDA, Alfredo Wagner Berno de (Orgs)... [et al]. Cadernos de debates Nova Cartografia Social: Territórios quilombolas e conflitos. Manaus: Projeto Nova Cartografia Social da Amazônia / UEA Edições, 2010. 349 p.

OLIVEIRA, Osvaldo Martins de. Quilombos: Memória Social e Metáforas dos Conflitos Comunidades do Sapê do Norte, Espírito Santo. In: ALMEIDA, Alfredo Wagner Berno de (Orgs)... [et al]. Cadernos de debates Nova Cartografia Social: Territórios quilombolas e conflitos. Manaus: Projeto Nova Cartografia Social da Amazônia / UEA Edições, 2010. 349 p.

PACHECO, Tânia. Inequality, Environmental Injustice, and Racism in Brazil: Beyond the Question of Colour. Development in Practice. Vol. 18, No. 6 (Nov. 2008), pp. 713-725 Disponível em: «http://www.jstor.org/ stable/27751978. Acesso em: 22 dez. 2016.

RATTS, Alex; FURTADO, George. Observações Sobre a Situação dos Quilombos em Goiás. In: ALMEIDA, Alfredo Wagner Berno de (Orgs)... [et al]. Cadernos de debates Nova Cartografia Social: Territórios quilombolas e conflitos. Manaus: Projeto Nova Cartografia Social da Amazônia / UEA Edições, 2010. 349 p.

ROJAS MARTÍNEZ, Axel Alejandro ¿Qué pasaría si la escuela...? 30 años de construcción de una educación propia. Programa de Educación Bilíngüe e Intercultural del Consejo Regional Indígena del Cauca, CRIC, 2004. Revista Colombiana de Educación, núm. 48, enero-junio, 2005, pp. 199-203. Universidad Pedagógica Nacional Bogotá, Colômbia.

SANTANA-FILHO, Diosmar. A geopolítica do Estado Nacional e a territorialidade quilombola na Bahia no séc. XXI. Dissertação de Mestrado. Universidade Federal da Bahia, Instituto de Geociências, 2014. $228 f$. 
SATO, Michèle. Ecofenomenologia: uma janela ao mundo. Revista Eletrônica do Mestrado em Educação Ambiental, FURG, edição especial 2016.

. Envolver em vez de se "des-envolver". IHU ON-LINE Revista do Instituto Humanitas Unisinos. SÃO LEOPOLDO: No 433- Ano XIII, 2013 - ISSN 1981-8769.

Cartografia do imaginário no mundo da pesquisa. In: ABÍLIO,

F. (Org.) Educação Ambiental para o Semiárido. João Pessoa: EdUFPB, p. 539-569, 2011.

- Em busca de sociedades sustentáveis. Pátio - Revista Pedagógica: Educação para o desenvolvimento sustentável. Porto Alegre: ano XII, mai/jul, 2008, p. 55-59.

SATO, Michèle; PASSOS, Luiz Augusto. Arte-Educação-Ambiental. Ambiente \& educação. vol. 14, p. 43-59. 2009.

. Biorregionalismo: identidade histórica e caminhos para a cidadania. In LOUREIRO, C.F.B.; LAYARGUES, P. \& CASTRO, R.S. (Orgs.) Educação ambiental: repensando o espaço da cidadania. São Paulo: Cortez, 2002, p. 221-252.

SATO, Michèle. Apaixonadamente Pesquisadora em Educação Ambiental. EDUCAÇÃO: Teoria e Prática - vol. 9, nº 16, jan.-jun.-2001, p. 24-35.

SOUZA, Arivaldo Santos de;. S.; OLIVEIRA, Thiago Pires. Racismo Ambiental na llha do Cururupeba. In: Semana de Mobilização Científica da Universidade Católica do Salvador - SEMOC/UCSal. Anais da SEMOC, 2004.

SILVA, Regina. Do invisível ao visível: o mapeamento dos grupos sociais do estado de Mato Grosso - Brasil. 221f. Tese (Doutorado em Ecologia e Recursos Naturais) - Universidade Federal de São Carlos, São Carlos, 2011.

SILVA, Givânia Maria da. Vencer o Racismo Institucional: Desafios da Implementação das Políticas Públicas para Comunidades Quilombolas. 
In: ALMEIDA, Alfredo Wagner Berno de (Orgs)... [et al]. Cadernos de debates Nova Cartografia Social: Territórios quilombolas e conflitos. Manaus: Projeto Nova Cartografia Social da Amazônia / UEA Edições, 2010. 349 p.

SILVA, Regina; JABER, Michelle; SATO, Michèle. Tecendo a Educação Ambiental com fios amazônicos. R. Educ. Públ. Cuiabá, v. 19, n. 39, p. 115-130, jan./abr. 2010

WALSH, Catherine. Interculturalidade critica y pedagogia de-colonial: Insurgir, re-existir y re-vivir. In: CANDAU, Vera Maria Ferrão (Org.). Educação intercultural na América Latina: entre concepções tensões e propostas. Rio de Janeiro: Editora 7 Letras. 2010.

. Interculturalidade crítica e pedagogia decolonial: in-surgir, re-existir e re-viver. In. CANDAU, Vera Maria (Org.). Educação intercultural na América Latina: entre concepções, tensões e propostas. Rio de Janeiro: 7 Letras, 2009. p. 12-43. 